\title{
The Establishment of China Low-Carbon Legislation and System
}

\author{
Boyu Zhu \\ School of Law, Shandong University \\ Jinan 250100, Shandong, China \\ School of Law, Shandong University of Technology \\ Zibo 255049, Shandong, China \\ zhuboyu123@126.com
}

Keywords: low-carbon development; legislation; system

Abstract. The legislative system of Chinese low-carbon development includes the constitutional level, the basic law level and specialized legislative level, as well as local legislative level. In order to respond to low-carbon development, we should make low-carbon development strategies and national cycle development and green development as declaratory provisions when we revise our "Constitution Law". We should put low-carbon development into practice through "Environmental Protection Law". Furthermore, we should develop "Low Carbon Development Promotion Law" which can regulate the fundamental and comprehensive problems of low-carbon development. It should also speed up the local legislation of carbon trading emissions and carbon sinks. Besides, we must also highlight the planning system in particular low-carbon development, low-carbon industry directory and exit system, carbon assessment and carbon emissions target responsibility system.

\section{Introduction}

Low-carbon development is a huge project. Thus, we should diversify the legislation to accelerate low-carbon development. Complete legislative system and good legal system is an important guarantee for the success of low-carbon development. China should learn low-carbon development legislative experience from developed countries, integrate the existing low-carbon development policies and laws, constantly supplement and improve the content of the legislative system of low-carbon development, construct the legislative system which fully embodies the concept of sustainable development, and improve the legal system of low-carbon development.

\section{Rational Design of Chinese Legislative System of Low-Carbon Development}

The legislative system of Chinese low-carbon development includes the constitutional level, the basic law level and specialized legislative level, as well as local legislative level.

\section{Constitutional law level}

In the field of low-carbon development, "constitutional" provisions on low-carbon development is the foundation for the development of low-carbon legislative system. As the constitution law does not establish environmental priority principle, it does not reflect the concept of sustainable development and ecological civilization and it does not provide regulations for low-carbon development. The current constitution law in China promulgated in 1982, when the environmental problems didn't cause enough attention. After revised in 1988, 1993, 1999 and 2004, our constitution law has formed the economic system which can adapt to economy development. However, the environmental protection clause in the constitution is still very rare.

As the mother law of other laws, the constitution law has supreme legal authority. Thus, as a basic national policy of economic and social future, environmental protection clause should be clarified in the fundamental law. When we revised our constitution law next time, we should integrate the existing low-carbon development policies and laws, supplement and improve the content of the legislative system of low-carbon development and make declaratory provision for low-carbon development and 
green development. Only in this way, can the fundamental law of the country under the guidance will be incorporated into low-carbon development in other branches of law, constitute an organic legislative system in order to achieve the overall goal of low-carbon development.

\section{Basic law level}

Environmental protection law is the basic and comprehensive law of ecological and environmental protection. With the "environmental constitutional" status, this law plays a significant role in the legislative system. The article 1 of the newly revised "Environmental Basic Law" in 2014 has defined the general purpose of this act, "to protect and improve the environment, prevent pollution and other public hazards, safeguard public health, promote the construction of ecological civilization, and promote sustainable economic and social development". Simultaneously, in general article 6, it regulates as follows, "citizens should enhance the awareness of environmental protection, take a low-carbon and frugal lifestyle and conscientiously carry out their environmental protection obligations." This is the first time that "low-carbon" is regulated in China's basic law. But it does not provide further systems and detailed regulations for low-carbon development. Generally speaking, this basic law is not enough and functional for low-carbon development. To promote the construction of ecological civilization and sustainable development, the concept of low-carbon development should be introduced into basic law and formed a series of supporting measures and designed systems. At the basic law level of low-carbon development, we should also develop a "Low-carbon Development Promotion Law" which can integrate the fundamental and comprehensive problems of low-carbon development. After that, it can coordinate the relationship among different specialized laws and promote the healthy development of China's low carbon development. At the designed position level, the "Low-Carbon Development Promotion Act" should be designed the same status with "Circular Economy Promotion Law" and its status is below the "Environmental Protection Law". Undoubtedly, all these three laws belong to basic laws. Thus, the "Low-Carbon Development Promotion Law" reflects the principles of ecological civilization construction of China's low carbon development and regulates the principles, institutions, mechanisms and integrated system of low-carbon development. As the axis of the entire low-carbon development legislative framework, under the guidance of the basic law, this law will plays an important position and role in economic and social development. At the same time, it should take precedence in the act and set up the national security mechanism under the international convention as Chinese promised. At the technical legislation level, we have to overcome some drawbacks in China's existing legislation, such as duplicate legislation, cross-legislation. Based on the idea of balance the economic and social development, the law should focus on "low carbon development", reduce duplication with the "Environmental Protection Law" and "Circular Economy Promotion Law" and other laws. At the legislative character level, we should clarify the low-carbon development law as the "Promotion Act." Firstly, it should illustrate the basic concept of "low carbon", "carbon emission" and other definitions and convert these concepts from theoretical concept to legal concept. Internationally, the "Framework Convention" has defined the concepts of "climate change", "greenhouse gases" and "discharge" and so on. Besides, in the abroad legislative practice, South Korea has defined the "low carbon"," green growth "," greenhouse gases "," greenhouse gas emissions "and other basic concepts in its "Low-Carbon Green Growth Law".[1] All these above legislative experiences can provide references for China.

\section{Specialized legislative level}

Until now, the necessary legislation of low-carbon development in China are still missing, many fields are still blank. The existing regulations are mainly enacted by several National Development and Reform Commission (or the relevant departments). However, the involved low-carbon development regulations and rules are not detailed enough. Since the low-carbon development problem is in essence the energy problem, so we should first deal with a good relationship with the existing Energy Law and low-carbon development. It should be injected into a low-carbon concepts, methods and systems in energy legislation and combine energy with low-carbon. Besides, we should pay more attention to energy law and make "Energy Act" as "top priority". Then, we can build a good low-carbon 
development legislative system, which is the main contents and key issues of current legislation of China's low carbon development.

"Energy Act" is a comprehensive legislation in the energy field. Since started to draft "Energy Law" in 2005, it has been lasted ten years. But it still not submitted to the NPC or its Standing Committee yet. After the 2008 manuscript, it has been put into consideration again in the second session of the NPC Standing Committee to adjust the five-year legislative plan in 2015. During the drafting process, it should take the low carbon development concept into account. At the legislative purpose level, we should mainly focus on the concept of sustainable development, standardize the utilization and management of energy, optimize energy structure and improve energy efficiency. We should establish the energy, energy resources, strategic position in the energy industry and infrastructure.

In the traditional areas of conventional energy, it mainly includes coal, oil and gas, electricity and so on. Although the "Coal Law" has been revised in 2011 and 2013, it still exists a lot of problems; Furthermore, China has not yet a complete and unified "Oil and Gas Law" and the existing laws is the "Mineral Resources Law" ; The "Electricity Law" which was revised in 2009 has been unable to meet the new situation and the need for new situations. We should draw on the useful experience of the world, take the energy and ecological environmental development concept as a legal principle, clear its priority, change the thinking of "highlight the regulation in the end and ignore the control at the source", establish full control concepts and improve the development of clean conventional energy production system. In the "Coal Law", we should increase the carbon emissions control provisions and clean coal technologies regulations; formulated the "oil and gas law" which should uphold the idea of sustainable development and avoid taking the old path of pollution first and treatment last in developed countries; In the "Electricity Law", we should add provisions on renewable energy and thermal power generation or carbon capture and storage technology and other aspects, build a green certificate system and promote the improvement of green electricity. In the field of renewable energy legislation, it mainly refers to "Renewable Energy Law." As the main form of clean energy, renewable energy has become alternative energy of low-carbon development. Promotion the use of renewable energy, it can greatly reduce non-renewable energy development and utilize "high-carbon" pressure. Renewable energy itself is a kind of low-carbon energy. However, we should introduce the "low carbon" concept into China's renewable energy legislation and realize "low-carbon" in the system design. In the field of energy legislation, we can improve the "Energy Conservation Law" and relevant laws and regulations. Reduce energy use and improve energy efficiency would mean to reduce carbon emissions. But the law of "energy conservation" did not directly include "reducing carbon emissions". We should put the content of "carbon reduction" into the concept of "energy saving". .

In China, we should also speed up the legislation of carbon emissions trading. Since 2005, Europe and America has launched or implemented a carbon emissions trading laws and achieved remarkable results. As a typical representative of new emerging economies, under the dual pressures from the international and domestic aspects, China has started the "two provinces and five cities" carbon emissions trading pilot and plans in the end of 2011 and it plans to open the national carbon market in 2016. All the pilots focus on the key institutional elements and technical requirements in the carbon markets, they completed a key system design and launched a carbon trading in a short time. But China lacks national law in seven pilots. Shenzhen and Beijing have local legislation and regulations, and Shanghai, Guangdong, Tianjin, Hubei and Chongqing are local government regulations which is legally binding weak. Meanwhile, although all the pilots basically completed the technical development in the policy aspects, such as carbon emissions trading rules and MRV guidelines. But it did not form into laws and regulations. If we want to build a national carbon market, we need to fully consider China's economic structure, energy structure, emission reduction targets, abatement costs, as well as our regional and industry conditions and large differences in coverage, then we need to pay attention on the total amount of settings, quota allocation, offset mechanisms, market key institutional trading and compliance mechanism and other elements of design. Besides, we can set the emission reduction targets, enact the relevant laws, use price measures, balance economic growth and energy saving, and guide enterprises to minimize the cost to achieve emission reduction targets. [2] At the same time, we 
should accelerate the development and promotion of emissions control technology, make laws to encourage financial institutions to support low-carbon development, and improve the establishment of green funds and so on.

In addition, at the aspect of carbon sinks, we should accelerate the amendments to the legislation. At present, there are two possible paths to carbon sinks. One is to increase forest carbon sinks and the other is to increase soil carbon sequestration. The existing "Forest Law" focuses on economic development and neglects the ecological benefits. We should change this situation and introduce the concept of sustainable development. The current "Forest Law", "Agriculture Law," "Grassland Law", "Water and Soil Conservation Law" and other laws don't describe the value of carbon sequestration in agricultural land and grasslands. So we should reflect the idea and value of ecological and environmental protection in the process of law revision.

\section{Local legislation level}

Because of China's vast territory, the development level of each region is relatively unbalanced. This objective reality determines that the legislation can not realize the unit and detailed rules in the national level. So we must recognize that local legislation plays important role for low-carbon development. According to the amendments of "Legislation Law" in 2015 , the People's Congress and its Standing Committee of provinces, autonomous regions and municipalities have the power to enact local regulations; these local governments have the power to enact local regulations; autonomous areas have the right to formulate autonomous regulations and separate regulations. All these amendments have provide conditions to the local low carbon development legislation. According to the need to local conditions, under the guidance of basic laws, the local governments should develop locally appropriate low-carbon development local laws and regulations. In this regard, the relevant US state legislative experience is worth learning. Currently, some provinces in China and even some cities have issued regulations to promote low-carbon development, vigorously promote the expansion of low-carbon development. The efforts in this area should be vigorously strengthened.

\section{The establishment of the relevant legal system of low-carbon development}

Institutional innovation is the key to low-carbon development legislation. In the process of promoting low-carbon economy, in addition to adhere to effective environmental legal system in the past, we must also highlight the planning system in particular low-carbon development, low-carbon industry directory and exit system, carbon assessment and carbon emissions target responsibility system.

\section{Planning system}

To promote the orderly development of low-carbon economy, it should make scientific strategic plans of low-carbon development. In the field of low-carbon development, the State Council formulated the " comprehensive program of work in low-carbon economy". In effect, each province and city also started a low-carbon economic planning strategy and the corresponding experimental zones. Such as Guangdong Province has launched a "low-carbon roadmap and policy research promotion in Guangdong Province " and other strategic research projects. [3] We shall define the future of low-carbon emission reduction targets and specific regulation time period, make overall plans of low-carbon emission and improve the low-carbon taxation and finance, credit, energy conservation, low-carbon technology and other follow-up support means. Of course, the introduction of the scientific strategy of development is directly related to the global economy, we must also pay attention to the importance of strategic environmental impact assessment before planning the introduction of the environmental impact statement. In order to establish the long-term mechanism to a low-carbon development, we should also highlight the guiding role of government, put the low-carbon development into relevant plans, create a clear policy and legal framework to develop low-carbon development plan, set developing goals and make long-term development strategy and plan . 


\section{Standard system}

Low-carbon development requires to control greenhouse gas emissions activity. Therefore, we should predict and judge the load of atmospheric environment based on scientific and quantitative methods. The greenhouse gas emission control related standards includes atmospheric environmental quality standards, greenhouse gas emission standards, greenhouse gases detection standard and energy efficiency standards. [4] Due to global warming both involving the use of atmospheric environmental capacity and energy use activities, it leads to the control of greenhouse gas emissions associated with standard integration of environmental standards and energy efficiency standards. Therefore, in the field of low-carbon development, standard system refers to the relevant provisions of environmental standards and energy efficiency standards. Besides, the modification, sorting, grading, standards limit the force of law, the legal significance, application and supervision of relevant legal norms are also included. [5] The standard system of science and technology can make the abstract concrete specification and it also help to enhance the clarity of law. Standard system also has a prediction and guidance function, in order to avoid the cost of illegal or obtain permission, greenhouse gas emissions will be the main reference standards for action. We should learn from the experiences of United States which made the "Oregon Energy Equipment carbon dioxide emissions standards" in 1997. China can set our own standard system.

\section{Licensing system}

Greenhouse gas emission allowances refers to the body who are engaged in legal activities of the main greenhouse gas emissions, according to the law, apply to the administrative department, after examination and approval by the competent administrative authorities to grant licenses in the form of grant applicants in specific greenhouse gas emissions. In this aspect, British has success experience. It make "greenhouse gas emissions trading regulations 2003"which has the provisions of any other body in the statutory greenhouse emissions activities must apply the permits and licenses to the authorities. [6] China should also create this kind of "command - control" system.

\section{Lower industrial directory and exit system}

Under the overall national industrial policy framework, the development of low-carbon industrial directory should be set up. We should create the directory and promote the implementation.

Specifically speaking, we can make policies standards to phase-out the lag-behind technology and encourage enterprises to adopt the technology of high-carbon low-carbon transformation.

\section{Carbon assessment and carbon emissions target responsibility system}

In the implementation of environmental impact assessment and three simultaneous system, we should also set and promote the legal system carbon assessment. In the project proposal preparation stage, we should analyze the assessment of the environmental impact and assess the carbon emissions. The implementation of low-carbon development should focus on carbon assessment and set energy conservation target responsibility system. In this process, the role of government is important. The system of energy-saving targets responsibility clarify the responsibilities of the government, strengthen the energy saving statistics monitoring system and link the performance assessment with energy conservation target responsibility. Establish a carbon emissions target responsibility legal system can also greatly promote the development of low-carbon economy. [7]

\section{Conclusions}

China should be based on national conditions and reasonably learn from Western countries to promote low-carbon development legislative experience. We should clarify the basic idea, solid legislative foundation, make good scientific planning, illustrate scientific design of low-carbon development and then establish the legal system and orderly promote the development of low-carbon legislation. 


\section{Acknowledgements}

The article is a part of National Social Science Fund Project "Efficiency of Environmental Law Enforcement" (No: 13BFX130), Research Project of Social Science in Shandong Province "Legal Research Policy For Low Carbon Development" (No: 13BFXJ05), Research Project of Shandong Province Law Society(No: SLS(2015)G58).

\section{References}

[1] Zheng, Tongtong. Low Carbon Green Growth of Korea Basic Law(Revised in 2013). Journal of Nanjing University of Technology, No.3, 23-24. (2013).

[2] Information on http://m.haokoo.com/mobi/view/2777594.html

[3] Wang, Xiaolin. The relationship of low carbon economy and the rule of law. People's Congress report. (2010).

[4] Liu, Mingming. Research on the legal system of controlling greenhouse gas emissions. Law Press, Beijing, 2012, pp.100.

[5] Yang, Zhaoxia. Research on the legal status of environmental standards - Review and supplement to mainstream views. Administration and Law, No. 1, 110. (2008).

[6] Liu, Mingming. Research on the legal system of controlling greenhouse gas emissions. Law Press, Beijing, 2012, pp.108.

[7] Qi, Ye. Report on China Low Carbon Development(2011-2012). Social Sciences Academic Press, pp.146-150. (2012). 